\title{
Alpha-Hemoglobin-Stabilizing Protein: An Erythroid Molecular Chaperone
}

\author{
Maria Emília Favero ${ }^{1,2}$ and Fernando Ferreira Costa ${ }^{2}$ \\ ${ }^{1}$ Department of Pathology, Clinical Analysis and Toxicology, University Hospital, State University of Londrina (UEL), \\ Avenida Robert Koch, 60, Vila Operária, 86038-350 Londrina, PR, Brazil \\ ${ }^{2}$ Hematology and Hemotherapy Center, State University of Campinas (UNICAMP), Rua Carlos Chagas, 480, \\ Cidade Universitária, Barão Geraldo, 13083-970, Campinas SP, Brazil \\ Correspondence should be addressed to Fernando Ferreira Costa, ferreira@unicamp.br
}

Received 29 July 2010; Accepted 19 December 2010

Academic Editor: Francesca Cutruzzolà

Copyright ( $) 2011$ M. E. Favero and F. F. Costa. This is an open access article distributed under the Creative Commons Attribution License, which permits unrestricted use, distribution, and reproduction in any medium, provided the original work is properly cited.

\begin{abstract}
Alpha-hemoglobin-stabilizing protein (AHSP) is an erythroid-specific protein that acts as a molecular chaperone for the free $\alpha$ chains of hemoglobin. Evidence strongly suggests that AHSP participates in hemoglobin synthesis and may act to neutralize the cytotoxic effects of excess free alpha-globin subunits that accumulate both in normal and beta-thalassemic erythroid precursor cells. As such, AHSP seems to be essential for normal erythropoiesis, and impaired upregulation of AHSP may lead to premature erythroid cell death, resulting in ineffective erythropoiesis. Reduced AHSP mRNA expression has been associated with clinical variability in some cases of $\beta$-thalassemia. It has been shown that $\alpha \mathrm{Hb}$ variants may also impair AHSP- $\alpha \mathrm{Hb}$ interactions, leading to pathological conditions that resemble $\alpha$-thalassemia syndromes. The aim of this paper is to summarize current information concerning the structure and function of AHSP, focusing on its role in normal erythropoiesis and its relevance in health and disease.
\end{abstract}

\section{Introduction}

The term "molecular chaperone" was first used in 1978 to describe the in vitro properties of nucleoplasmin, which prevents the aggregation of folded histone proteins with DNA during the assembly of the nucleosome [1]. However, the concept of the molecular chaperone as a protein that can interact with other proteins and help them to reach their final, active conformation was established only in 1987 [2]. Molecular chaperones are currently defined as "proteins whose role is to mediate the folding of certain other polypeptides and, in some instances, their assembly into oligomeric structures, but which are not components of these final structures" [3]. As such, molecular chaperones participate in a variety of physiological processes related to the correction of the structure of proteins during their synthesis and after their release from ribosomes, and more than 25 different protein families described as chaperones have been reported [4].
Alpha-hemoglobin-stabilizing protein (AHSP) is a small protein that binds specifically to the free alpha globin chain $(\alpha \mathrm{Hb})$ of hemoglobin $(\mathrm{Hb})$. The main function of AHSP appears to be to regulate the stability, folding, and assembly of the $\alpha \mathrm{Hb}$ subunit. The biochemical properties of the AHSP- $\alpha \mathrm{Hb}$ complex led to the classification of AHSP as a novel type of chaperone. Like the small heat shock proteins (sHSPs), a family of molecular chaperones, AHSP presents low molecular weight and ATP-independent chaperone-like activity. However, unlike other molecular chaperones, it does not form oligomeric complexes and is highly tissue and substrate specific $[5,6]$. AHSP plays an important role in the physiological process of erythropoiesis $[5,7]$ and may also be a modulator of pathological conditions [8-11]. Since chaperone proteins are essential for native protein conformation and defective chaperone proteins may be associated with diseases, the aim of this paper is to summarize the current research concerning the structure and function of AHSP, focusing on its role in normal 
erythropoiesis and its possible importance as a modifier of $\beta$-thalassemia.

\section{Hemoglobin: Function and Biosynthesis}

Hemoglobin is an essential protein for life, since it is responsible for binding oxygen in the lungs and delivering it to all tissues and organs in the body in a well-controlled manner. The major functional adult human $\mathrm{Hb}(\mathrm{HbA})$ is a heterotetramer composed of two alpha- $(\alpha \mathrm{Hb})$ and two beta$(\beta \mathrm{Hb})$ globin chains, each containing a prosthetic groupHeme [12].

Biosynthesis of hemoglobin occurs exclusively in cells of erythroid lineage and, therefore, is intimately related to erythropoiesis. Hemoglobin synthesis begins at the proerythroblast phase, continues at a high rate throughout the basophilic and the polychromatophilic erythroblast stages, and persists at a very low rate in the reticulocytes. This multistep process is complex and controlled by two distinct gene clusters: the $\alpha$-like globin cluster located on chromosome 16 and the $\beta$-like globin cluster on chromosome 11; and is highly regulated to ensure that $\alpha \mathrm{Hb}$ and $\beta \mathrm{Hb}$ are produced at a stoichiometric rate. During the first step of $\mathrm{HbA}$ assembly, $\alpha \mathrm{Hb}$ and $\beta \mathrm{Hb}$ chains combine to form the $\alpha_{1} \beta_{1}$ interface, which involves hydrophobic and electrostatic interactions. In a second step, two dimers associate to form the $\alpha_{1} \beta_{2}$ interface, which involves more polar interactions [12]. Isolated $\alpha \mathrm{Hb}$ is different from $\beta \mathrm{Hb}$ monomers in structural stability, where $\beta \mathrm{Hb}$ subunits are more stable than $\alpha \mathrm{Hb}$. After covalent association with heme, $\beta \mathrm{Hb}$ chains self-associate to form homotetramers $\left(\beta_{4}\right)$, called $\mathrm{HbH}$. However, these tetramers are not functional due to their high affinity for oxygen. During auto-oxidation, $\alpha \mathrm{Hb}$ monomers tend to produce reactive oxygen species (ROS) via chemical reactions catalyzed by heme-iron [13]. Free $\alpha \mathrm{Hb}$ monomers are highly unstable and do not self-associate to form tetramers but tend to aggregate and precipitate, resulting in damage to the membrane and triggering the apoptosis of erythroid precursors (ineffective erythropoiesis) and a shortened lifespan of circulating red blood cells [14, $15]$.

Before the discovery of AHSP protein, it was postulated that the nascent polypeptide chains readily associate to form dimers $(\alpha \beta)$, and soon after, to form tetramers $\left(\alpha_{2} \beta_{2}\right)$ by a spontaneous process requiring no other molecules [16, 17]. This concept changed after Kihm and colleagues [6] showed that the small protein AHSP, encoded by a gene first described as EDRF [18], could form a complex with free $\alpha \mathrm{Hb}$, preventing its precipitation and neutralizing its deleterious effects. Currently, AHSP is known to play an important role in hemoglobin assembly and could have medical implications, since imbalances in globin synthesis are associated with serious human diseases [14]. In thalassemia disorders, mutations in the $\alpha$-globin $(H B A)$ or $\beta$-globin $(H B B)$ genes lead to an excess of free $\beta \mathrm{Hb}$ or $\alpha \mathrm{Hb}$ subunits, respectively. Due to the great variability in $\beta$-thalassemia phenotype and the role of AHSP in preventing the cytotoxic effects of free $\alpha \mathrm{Hb}$ in excess, it has been suggested that AHSP is a potential modifier of this disease.

\section{AHSP: An Erythroid Molecular Chaperone}

AHSP is a protein expressed in hematopoietic tissues (bone marrow in humans and fetal liver, spleen, and bone marrow in mice) and exclusively by cells of the erythroid lineage $[6,18]$. AHSP forms a stable but reversible complex with free $\alpha \mathrm{Hb}$ to stabilize its structure and limit its chemical reactivity. This interaction prevents $\alpha \mathrm{Hb}$ aggregation and precipitation in solution and in live cells and therefore maintains $\alpha \mathrm{Hb}$ available for incorporation into $\mathrm{HbA}[6,19]$. The AHSP- $\alpha \mathrm{Hb}$ interaction also inhibits ROS production and, therefore, oxidative damage $[20,21]$. AHSP does not bind to the $\beta \mathrm{Hb}$ subunit or tetrameric $\mathrm{HbA}$. Indeed, structural analysis of AHSP- $\alpha \mathrm{Hb}$ complex revealed that AHSP and $\beta \mathrm{Hb}$ compete to bind to $\alpha \mathrm{Hb}$ in the same region, called the $\alpha_{1} \beta_{1}$ interface [5]. $\beta \mathrm{Hb}$ affinity to $\alpha \mathrm{Hb}$ is stronger and wins this competition, displacing AHSP to form the $\mathrm{HbA}$ molecule. Consistent with the role of a molecular chaperone, in addition to its ability to stabilize $\alpha \mathrm{Hb}$, AHSP is also able to promote refolding of denatured $\alpha \mathrm{Hb}$ [22].

\section{AHSP: Gene Structure and Expression}

The AHSP gene is located on human chromosome 16 (GenBank accession number AC106 730.2). The genomic structure of AHSP is organized in three exons and two introns, comprising approximately $1.8 \mathrm{~kb}$. The AHSP mRNA encodes a protein of 102 amino acids with a molecular mass of $12 \mathrm{kDa}$; the protein is highly conserved in humans, pigs, cows, and rats [6].

Identification and characterization of the regulatory elements that control AHSP gene expression have important implications for normal erythropoiesis and the pathogenesis of hemolytic disorders. Like many other genes that participate in hemoglobin synthesis, AHSP gene expression is controlled by GATA-1 [6], a transcription factor that is essential for the survival and maturation of lineagecommitted erythroid precursors. There is evidence that Oct1 [23] and EKLF [24-26], two transcription factors that have a critical role in erythropoiesis, also participate in the control of AHSP gene expression.

The AHSP gene promoter comprises the region from -170 to +269 and includes the $5^{\prime}$-flanking DNA and intron 1. There are 5 consensus GATA- 1 binding sites in this minimal promoter region $(-179 /+290)$, three in the $5^{\prime}$ flanking region and two in intron 1 . An Oct- 1 consensus site also exists in the AT-rich region of AHSP intron 1 [23]. EKLF directly regulates the $A H S P$ gene by binding to a site at -60 in the human AHSP promoter region that is situated between two conserved GATA- 1 binding sites at -47 and -90 . Keys and colleagues [25] proposed that GATA-1 and EKLF are coregulators of $A H S P$ gene expression during erythropoiesis.

Molecular analysis of the AHSP gene has identified several single nucleotide polymorphisms (SNPs) and gene haplotypes $[9,10,27]$. An SNP within the intron 1 of AHSP 
(12391 G > A SNP) alters the binding site for Oct-1, and there is evidence that this SNP can reduce AHSP expression in vivo [10]. Human AHSP gene expression can be affected by the iron status via an iron sensor system, composed of iron responsive elements (IREs) and iron regulatory proteins (IRP). A stem-loop structure that resembles the IRE was identified in the $3^{\prime} \mathrm{UTR}$ of AHSP mRNA. It has been shown that these IRE-like structures can interact with IRPs and that the IRE-IRP interactions can be disrupted by iron, resulting in destabilization of AHSP mRNA. These data suggest that AHSP gene expression is downregulated in the excess of iron and upregulated during iron deficiency [28].

\section{AHSP: Protein Structure and Mechanism of Action}

The structure of AHSP was determined by nuclear magnetic resonance spectroscopy (NMR) and X-ray crystallography $[20,21,29]$. In its native state, AHSP is comprised of a bundle of three elongated antiparallel $\alpha$-helices and is conformationally heterogeneous. AHSP exists in two forms, cis and trans, that are distinguished because of the arrangements of the loop region between helices 1 and 2 due to cis/trans isomerization of residue Pro30. However, once AHSP binds to $\alpha \mathrm{Hb}$, Pro30 adopts just one conformation [29].

AHSP forms a simple heterodimer with $\alpha \mathrm{Hb}$ via the $\alpha_{1}$ portion of the $\alpha_{1} \beta_{1}$ interface in $\mathrm{HbA}$ [5], which is the same interface as that of the $\beta \mathrm{Hb}$ interaction. The intermolecular contacts between $\alpha \mathrm{Hb}$ and AHSP are less extensive than those between $\alpha \mathrm{Hb}$ and $\beta \mathrm{Hb}$ and this may explain why AHSP is replaced by $\beta \mathrm{Hb}$ [11]. AHSP binds apo- $\alpha \mathrm{Hb}$ (without heme) and holo- $\alpha \mathrm{Hb}$ (with heme iron), either in the oxidized (FeIII) or reduced (FeII) states $[5,6$, $20,21]$. Data suggest that the interaction of wild-type AHSP (AHSP ${ }^{\mathrm{WT}}$ ) with nascent $\alpha \mathrm{Hb}$ promotes correct folding into a native state, which is independent upon heme, conferring protection from proteolytic digestion. Consistent with the role of a molecular chaperone, AHSP also promotes refolding of denatured apo- $\alpha \mathrm{Hb}$ [22].

Reports indicate that binding of AHSP to oxy- $\alpha \mathrm{Hb}$ (FeII) is associated with structural alterations in the heme pocket. These initial changes are reversible and result in a structure that exposes the oxygen-binding site $[21,30]$. If the oxy- $\alpha \mathrm{Hb}$-AHSP interaction persists, the structure of the heme pocket is altered further, auto-oxidation occurs and the heme-bond iron is converted to a ferric form in a Fe(III) bis-histidyl complex. This hemichrome structure inhibits the reaction of $\mathrm{Fe}(\mathrm{III})-\alpha \mathrm{Hb}$ with oxidants such as hydrogen peroxide, conferring resistance to hemin loss and denaturation. AHSP, bound to both the oxidized (ferric) and reduced (ferrous) $\alpha \mathrm{Hb}$ forms, can be replaced by oxy- $\beta \mathrm{Hb}$ to generate functional $\mathrm{HbA}$ [30]. These data suggest that, in the absence of $\beta \mathrm{Hb}$, AHSP maintains the excess $\alpha \mathrm{Hb}$ in a reversible inert state to limit the production of damaging ROS.

The kinetics of $\alpha \mathrm{Hb}$ binding-dissociation to AHSP was investigated by Mollan et al. [31]. The authors used the fluorescence energy transfer technique to study the rate of association and dissociation of the AHSP- $\alpha \mathrm{Hb}$ complex.
The $\alpha \mathrm{Hb}$ and $\beta \mathrm{Hb}$ chains do not fluoresce due to high quenching of tryptophan or tyrosine fluorescence by the heme group, an efficient energy acceptor. AHSP has no heme group and demonstrates an intrinsic fluorescence typical of an exposed tryptophan at position 44 . As such, quenching of fluorescence of the AHSP by binding to $\alpha \mathrm{Hb}$ was used to measure the rate of AHSP- $\alpha \mathrm{Hb}$ complex formation. Starting the experiment with isolated $\alpha \mathrm{Hb}$ and AHSP proteins, these authors found that the apparent association rate constant for AHSP to $\alpha \mathrm{Hb}\left(k^{\prime} \approx 10 \mu \mathrm{M}^{-1} \mathrm{~s}^{-1}\right.$ ) is greater than the association rate constant for (deoxy) $\alpha \mathrm{Hb}$ to (deoxy) $\beta \mathrm{Hb}$ $\left(k^{\prime} \approx 0.5 \mu \mathrm{M}^{-1} \mathrm{~s}^{-1}\right)$ in in vitro experiments. The $\beta \mathrm{Hb}$ chains were added to follow the displacement of $\alpha \mathrm{Hb}$ from AHSP, and the increase in fluorescence intensity was used to detect the extent of AHSP dissociation. The dissociation equilibrium constant $\left(K_{d}\right)$ of $\sim 10^{-2} \mu \mathrm{M}$ for the AHSP- $\alpha \mathrm{Hb}$ complex was compared with the $K_{d}$ of $\sim 10^{-6} \mu \mathrm{M}$ for the $\alpha \mathrm{Hb}-\beta \mathrm{Hb}$ dimer. Thus, these data show that AHSP binds faster to $\alpha \mathrm{Hb}$ than $\beta \mathrm{Hb}(\sim 20$ times) and also that AHSP has a lower affinity for $\alpha \mathrm{Hb}$ when compared with the affinity of $\beta \mathrm{Hb}$ for $\alpha \mathrm{Hb}(\sim 10.000$ times). These kinetic properties of AHSP are in agreement with its chaperone function, that is, fast binding to free $\alpha \mathrm{Hb}$ to prevent its degradation and rapid release of $\alpha \mathrm{Hb}$ for $\mathrm{Hb}$ assembly [31].

\section{AHSP in Normal Erythropoiesis}

The main characteristic of erythropoiesis is the massive synthesis of hemoglobin. As stated earlier, $\alpha \mathrm{Hb}$ and $\beta \mathrm{Hb}$ subunits must be produced in equilibrium to prevent their harmful effects. However, there is experimental evidence that $\alpha \mathrm{Hb}$ is produced in slight excess during normal erythropoiesis. The identification of the AHSP gene by Miele et al. [18] and the recognition of its ability to specifically bind to free $\alpha \mathrm{Hb}$ by Kihm et al. [6] highlighted a new homeostatic mechanism to handle the harmful excess of free $\alpha \mathrm{Hb}$ during HbA production.

Using a murine model, Kihm et al. [6] reported the first evidence that AHSP plays an important role in in vivo erythropoiesis. Transgenic mice, in which the entire proteincoding region of Ahsp gene (Ash $\left.p^{-/-}\right)$was ablated, exhibited hematological alterations consistent with ineffective erythropoiesis that were similar to those observed in $\beta$-thalassemia. Unexpected results were obtained in a murine model of compound mutants lacking both Ahsp genes $\left(A s h p^{-/-}\right)$and 1 of $4 \alpha-H b$ genes $\left(\alpha H b^{-\alpha / \alpha \alpha}\right)$; these mice exhibit a more anemic phenotype than expected. These findings suggest that AHSP plays an important role in erythropoiesis even when the pool of free $\alpha \mathrm{Hb}$ is not present [22], probably because AHSP stabilizes newly synthesized $\alpha \mathrm{Hb}$ to augment its incorporation into $\mathrm{HbA}$.

The expression of the AHSP gene during human erythropoiesis was first reported by Dos Santos et al. [7]. Differentiation of erythroid progenitor cells from healthy volunteers was achieved by a two-phase liquid culture system, stimulated with erythropoietin. Cell surface marker expression was accompanied during cellular differentiation using flow cytometry and by morphological analyses. Quantification of $A H S P, H B A$, and $H B B$ gene expression was determined 
by the real time polymerase chain reaction at four distinct stages of erythropoiesis: during the earlier phase in which proerythroblasts begin to be discernible (3-4 days of phase II); during the intermediate phase characterized by the appearance of basophilic erythroblasts (5-7 days) and an increasing proportion of polychromatic and orthochromatic erythroblasts (8-10 days), and during the late phase in which orthochromatic erythroblasts predominate (11-14 days). Consistent with erythropoiesis physiology, higher levels of $H B A$ expression were observed during the intermediate phase, in which polychromatic and orthochromatic erythroblasts predominate, and it was followed by a decrease in more mature precursors, present during the late phase. Interestingly, AHSP expression during normal erythropoiesis showed a pattern similar to that of $H B A$, with the highest expression at the stage where hemoglobin biosynthesis is more intense. These data demonstrated that the ratio between AHSP and HBA expression is conserved in all stages of normal erythropoiesis and strongly suggest that AHSP plays an important role in human erythropoiesis [7].

To better understand the relationship between AHSP expression, HbA formation, and the consequences of a reduced AHSP synthesis in human red blood cells, an RNAinterference knockdown of AHSP expression was established both in hemin-induced K562- cells and human hematopoietic stem cells $\left(\mathrm{CD}_{3} 4^{+}\right)$. Decreased AHSP expression levels were observed in response to AHSP knockdown in both $\mathrm{K}$ 562 and EPO-induced CD34 ${ }^{+}$cells. The decrease in AHSP expression was associated with a remarkable $\alpha \mathrm{Hb}$ precipitation in erythroid precursors, when compared with negative control cells. Significant increases in ROS production and cell death were also observed [19]. These findings were in agreement with the data obtained in models of transgenic mice $[6,8]$ and provided further evidence that AHSP plays an important role in human erythropoiesis. Data from in vitro and in vivo studies suggest that AHSP participates in $\mathrm{HbA}$ formation by both preventing $\alpha \mathrm{Hb}$ precipitation and degradation or by enhancing proper folding and heme insertion [22, 32-34].

\section{AHSP as a $\beta$-Thalassemia Modifier}

Although $\beta$-thalassemia results from reduced $\beta \mathrm{Hb}$ synthesis, the pathophysiology of this disease is determined by the level of free $\alpha \mathrm{Hb}$ chains that cause oxidative damage of red blood cells. The marked variability in clinical severity of $\beta$ thalassemia has been attributed to environmental and genetic factors, including hereditary persistence of fetal hemoglobin (HPFH) and coexistence of $\alpha$-thalassemia [35]. However, these factors cannot explain the phenotypic variability in many cases of $\beta$-thalassemia.

Considering the biological and biochemical properties of AHSP, it is natural to speculate those AHSP mutations, leading to its reduced expression or altered function, could modify the clinical characteristics of $\beta$-thalassemia. Galanello et al. [36] provided the first evidence that AHSP could modulate $\beta$-thalassemia. They reported the association of reduced AHSP mRNA expression and a more severe phenotype among individuals with identical $\beta$-thalassemia genotypes in two unrelated Sardinian families. Observations from a murine model of $\beta$-thalassemia intermedia provided further evidence for this possibility. The phenotype of transgenic mice with $\beta$-thalassemia intermedia is exacerbated by concomitant AHSP loss [8]. AHSP mutations in $\beta$-thalassemia patients are uncommon and, to date, the association between AHSP mutation and $\beta$-thalassemia variability has not been well established; however, there exist some reports showing the association between $\beta$-thalassemia severity and AHSP genotype [10, 27, 37].

The investigation of AHSP sequence in healthy and $\beta$ thalassemia individuals from five different regions of the world identified a single nucleotide change in the third exon of the AHSP gene, resulting in a protein with an isoleucine at position 75 , instead of an asparagine $\left(\mathrm{AHSP}^{\mathrm{N} 75 \mathrm{I}}\right)$. This uncommon missense mutation does not affect the affinity of AHSP for $\alpha \mathrm{Hb}$ and the oxidation of the ferric oxy (FeII)$\alpha \mathrm{Hb}$ to the ferrous (FeIII) form is induced at a similar rate, when compared to the AHSP ${ }^{\mathrm{WT}}$. However, AHSP ${ }^{\mathrm{N} 75 \mathrm{I}}$ showed a reduced ability to inhibit ROS production by $\alpha \mathrm{Hb}$. Thus, there is evidence that the mutant protein is less effective against the oxidative effects of free $\alpha \mathrm{Hb}$. This mutation demonstrated clinical consequences in a patient, found to be compound heterozygous for AHSP ${ }^{\mathrm{N} 75 \mathrm{I}}$ and $\beta$-thalassemia $\left(\beta^{0}\right.$ Codon $\left.39 \mathrm{C}>\mathrm{T}\right)$, who presented with a severe anemia that required blood transfusion. However, when inherited without any thalassemia mutation, the heterozygous state does not show clinical relevance $[10,38]$.

Two other missense mutations, $\mathrm{AHSP}^{\mathrm{D} 29 \mathrm{~V}}$ (12750 A > $\mathrm{T})$ and $\mathrm{AHSP}^{\mathrm{V} 6 \mathrm{G}}(12831 \mathrm{~T}>\mathrm{G})$ were identified in a populational study to assess the effect of AHSP on the phenotype of $\beta$-thalassemia patients of Southern China, a region with a high prevalence of this genetic condition. However, neither of these mutations were associated with significant phenotypic variability among patients [39].

Lai et al. identified several sequence variants, including a Tn-homopolymer in the AHSP promoter region. In a family study, this AHSP variant, specifically the shorter homopolymer length $\left(\mathrm{T}_{15}\right)$, was associated with reduced AHSP-mRNA and protein expression in an individual with thalassemia syndrome (genotype $\beta^{0}{ }^{39-850 \mathrm{C}-\mathrm{T}} / \beta^{\mathrm{N}}, \alpha \mathrm{Hb}^{\alpha \alpha \alpha / \alpha \alpha}$, and $\mathrm{T}_{15} / \mathrm{T}_{18}$ ), when compared with her mother (genotype $\beta^{0}$ 39-850 C-T $/ \beta^{\mathrm{N}}, \alpha \mathrm{Hb}^{\alpha \alpha \alpha / \alpha \alpha}$, and $\left.\mathrm{T}_{18} / \mathrm{T}_{18}\right)$ [9]. However, no significant differences in hematological parameters were found among $\beta$-thalassemia carriers from Southern China who were $\mathrm{T}_{15}$ homozygous (14 cases), $\mathrm{T}_{18}$ homozygous (223 cases) or $\mathrm{T}_{15 / \mathrm{T} 18}$ heterozygous (128 cases) [39]. Conversely, Wang et al. showed that the introduction of a transgenic human-AHSP gene is able to neutralize excess $\alpha \mathrm{Hb}$ in a murine model of $\beta$-thalassemia $\left(\beta^{\mathrm{IVS}-2-654}\right)$ and, as a consequence, ameliorate the phenotype of these animals [40]. Despite the partial improvement observed in the approach described, these data support the hypothesis that AHSP could be an adjuvant in gene therapy to treat $\beta$-thalassemia.

\section{AHSP and $\alpha$-Thalassemia-Like Syndromes}

As stated previously, AHSP expression levels and protein function are important for the normal physiology of red 
blood cell production and could have a relevant impact on the phenotype of $\beta$-thalassemia. The level of AHSP mRNA from healthy individuals was not found to correlate with age or sex, but varied considerably, up to threefold in reticulocytes [9] and 10-fold in cultured erythroblasts [41]. This variability is probably associated with AHSP polymorphisms in regulatory regions since naturally occurring AHSP mutations that impair gene expression or protein function are rare $[9,10,27]$.

The mutant AHSP ${ }^{\mathrm{V} 66 \mathrm{G}}$ described by Pissard et al. [42] is the first mutation in the AHSP gene that can be associated with $\alpha$-thalassemia-like syndromes. The authors report the case of a child that presents with microcytic, hypochromic anemia, $3 \%$ of $\mathrm{Hb}$ Bart's, a normal globin gene pattern but a homozygous state for the AHSP ${ }^{\mathrm{V} 56 \mathrm{G}}$ mutant. The parents and the first son were heterozygous carriers for this mutation and were clinically normal [42]. The clinical feature observed in the homozygous state may be explained by the altered biochemical and biophysical properties of the mutant protein and its association with an haplotype characterized by a decrease in AHSP expression $[42,43]$. This mutation changes the Valine residue at position 56 to a Glycine. This residue is located at the corner between the two $\alpha$-helices [39, 43]. Investigating the kinetic properties of the AHSP ${ }^{\mathrm{V} 66 \mathrm{G}}$, Brillet and coworkers demonstrated that despite its thermal instability $\left(T_{\mathrm{m}}\right.$ of $42^{\circ} \mathrm{C}$ ), the binding to $\alpha \mathrm{Hb}$ and formation of the AHSP ${ }^{566}-\alpha \mathrm{Hb}$ complex is not affected. The association rate constant is similar to that of AHSP ${ }^{W T}$ $\left(k^{\prime} \approx 20 \mu \mathrm{M}^{-1} \mathrm{~s}^{-1}\right)$. In contrast, the $\mathrm{AHSP}^{\mathrm{V} 56 \mathrm{G}}-\alpha \mathrm{HB}$ complex dissociates faster (dissociation rate of $0.5 \mathrm{~s}^{-1}$ ) than AHSP ${ }^{\mathrm{WT}}$ $\left(2 \mathrm{~s}^{-1}\right)$, thus it seems that this reduced contact time does not allow the complex to complete the structural modifications required to stabilize $\alpha \mathrm{Hb}$ chains [43].

On the other hand, $\alpha \mathrm{Hb}$ mutations may also result in impaired AHSP- $\alpha \mathrm{Hb}$ interactions and could be responsible for thalassemia-like phenotypes without explanation in some patients. Indeed, this defective interaction has been shown for several $\alpha \mathrm{Hb}$ variants, such as $\mathrm{Hb}$ Constant Spring and Pakse [44]; Hb Groene Hart [45, 46]; Hb Foggia [47], and several other $\alpha \mathrm{Hb}$ variants [48, 49]. The structural abnormalities of these $\alpha \mathrm{Hb}$ variants are located at the AHSP binding interface, therefore impairing their interaction. Failed interactions may lead to destabilization of native $\alpha \mathrm{Hb}$ folding [48]. However, the mechanisms involved in this defective process are not well known, and further studies are required to better understand the biochemical and biological consequences of $\alpha \mathrm{Hb}$ variants.

\section{Summary and Perspectives}

Molecular chaperones are essential for the maintenance of their target proteins. AHSP is only expressed in erythroid cells, specifically binds to $\alpha \mathrm{Hb}$, and does not bind to $\beta \mathrm{Hb}$ or HbA. As a molecular chaperone for $\alpha \mathrm{Hb}$, AHSP plays at least three important roles: (a), promotes proper folding of nascent $\alpha \mathrm{Hb}$, independently of the presence of iron, conferring resistance to proteolytic digestion; (b), inhibits auto-oxidation of holo- $\alpha \mathrm{Hb}$, converting the bound heme iron to an inert hemichrome structure (c) it promotes refolding of the denatured protein. As such, AHSP seems to be essential for normal erythropoiesis. Impaired upregulation of AHSP leads to premature erythroid cell death, resulting in ineffective erythropoiesis. Reduced AHSP mRNA expression has been associated with clinical variability in some cases of $\beta$-thalassemia. It has been shown that $\alpha \mathrm{Hb}$ variants can also impair AHSP- $\alpha \mathrm{Hb}$ interactions, leading to pathological conditions that resemble $\alpha$-thalassemia syndromes. As such, AHSP mutations may be considered when clinical severity is not explained by the $\beta$-thalassemia genotype, or in undiagnosed $\alpha$-thalassemia-like syndromes.

Whilst available evidence strongly suggests that AHSP promotes the synthesis of $\mathrm{HbA}$ in red blood cells, future studies will help to better understand the molecular interactions of hemoglobin assembly and the relevance of these mechanisms in health and disease.

\section{Acknowledgments}

The authors would like to thank Dr. Nicola Conran for English review. The authors also thank CNPq, FAPESP, and INCT-Sangue for financial support.

\section{References}

[1] R. A. Laskey, B. M. Honda, A. D. Mills, and J. T. Finch, "Nucleosomes are assembled by an acidic protein which binds histones and transfers them to DNA," Nature, vol. 275, no. 5679, pp. 416-420, 1978.

[2] J. Ellis, "Proteins as molecular chaperones," Nature, vol. 328, no. 6129, pp. 378-379, 1987.

[3] R. J. Ellis, "Molecular chaperones: assisting assembly in addition to folding," Trends in Biochemical Sciences, vol. 31, no. 7, pp. 395-401, 2006.

[4] R. J. Ellis, "Molecular chaperones: the orthodox view," in Molecular Chaperones and Cell Signalling, B. Henderson and A. G. Pockley, Eds., pp. 3-21, Cambridge University Press, New York, NY, USA, 2005.

[5] D. Gell, Y. Kong, S. A. Eaton, M. J. Weiss, and J. P. Mackay, "Biophysical characterization of the $\alpha$-globin binding protein $\alpha$-hemoglobin stabilizing protein," Journal of Biological Chemistry, vol. 277, no. 43, pp. 40602-40609, 2002.

[6] A. J. Kihm, YI. Kong, W. Hong et al., "An abundant erythroid protein that stabilizes free $\alpha$-haemoglobin," Nature, vol. 417, no. 6890, pp. 758-763, 2002.

[7] C. O. Dos Santos, A. S. S. Duarte, S. T. Olalla Saad, and F. F. Costa, "Expression of $\alpha$-hemoglobin stabilizing protein gene during human erythropoiesis," Experimental Hematology, vol. 32, no. 2, pp. 157-162, 2004.

[8] YI. Kong, S. Zhou, A. J. Kihm et al., "Loss of $\alpha$-hemoglobinstabilizing protein impairs erythropoiesis and exacerbates $\beta$ thalassemia," Journal of Clinical Investigation, vol. 114, no. 10, pp. 1457-1466, 2004.

[9] M. I. Lai, J. Jiang, N. Silver et al., “ $\alpha$-haemoglobin stabilising protein is a quantitative trait gene that modifies the phenotype of $\beta$-thalassaemia," British Journal of Haematology, vol. 133, no. 6, pp. 675-682, 2006.

[10] C. O. Dos Santos, S. Zhou, R. Secolin et al., "Population analysis of the alpha hemoglobin stabilizing protein (AHSP) gene identifies sequence variants that alter expression and 
function," American Journal of Hematology, vol. 83, no. 2, pp. 103-108, 2008.

[11] M. J. Weiss, S. Zhou, L. Feng et al., "Role of alpha hemoglobin-stabilizing protein in normal erythropoiesis and $\beta$-thalassemia," Annals of the New York Academy of Sciences, vol. 1054, pp. 103-117, 2005.

[12] H. F. Bunn and B. G. Forget, Hemoglobin: Molecular, Genetic and Clinical Aspects, WB Saunders, Philadelphia, Pa, USA, 1986.

[13] M. Brunori, G. Falcioni, E. Fioretti, B. Giardina, and G. Rotilio, "Formation of superoxide in the autoxidation of the isolated $\alpha$ and $\beta$ chains of human hemoglobin and its involvement in hemichrome precipitation," European Journal of Biochemistry, vol. 53, no. 1, pp. 99-104, 1975.

[14] D. J. Weatherall, “Thalassaemia: the long road from bedside to genome," Nature Reviews Genetics, vol. 5, no. 8, pp. 625-631, 2004.

[15] E. Rachmilewtiz and S. L. Schrier, "Pathophysiology of $\beta$ thalassemia," in Disorders of Hemoglobin: Genetics, Pathophysiology and Clinical Management, M. H. Steinberg, B. G. Forget, D. R. Higgs, and R. L. Nagel, Eds., pp. 233-252, Cambridge University Press, New York, NY, USA, 2001.

[16] E. N. Dessypris and S. T. Sawyer, "Erythropoiesis," in Wintrobe's Clinical Hematology, J. P. Greer, J. Foerster, G. M. Rodgers et al., Eds., pp. 107-126, 12th edition, 2008.

[17] D. J. Weatherall, "The genetic control of protein synthesis: the haemoglobin model," Journal of Clinical Pathology. Supplement, vol. 8, pp. 1-11, 1974.

[18] G. Miele, J. Manson, and M. Clinton, "A novel erythroid-specific marker of transmissible spongiform encephalopathies," Nature Medicine, vol. 7, no. 3, pp. 361-363, 2001.

[19] F. O. Pinho, D. M. de Albuquerque, S. T. Olalla Saad, and F. F. Costa, "Reduction of AHSP synthesis in hemin-induced K562 cells and EPO-induced CD34 cells leads to $\alpha$-globin precipitation, impairment of normal hemoglobin production, and increased cell death," Experimental Hematology, vol. 36, no. 3, pp. 265-272, 2008.

[20] L. Feng, D. A. Gell, S. Zhou et al., "Molecular mechanism of AHSP-mediated stabilization of $\alpha$-hemoglobin," Cell, vol. 119, no. 5, pp. 629-640, 2004.

[21] L. Feng, S. Zhou, L. Gu et al., "Structure of oxidized $\alpha$ haemoglobin bound to AHSP reveals a protective mechanism for haem," Nature, vol. 435, no. 7042, pp. 697-701, 2005.

[22] X. Yu, YI. Kong, L. C. Dore et al., "An erythroid chaperone that facilitates folding of $\alpha$-globin subunits for hemoglobin synthesis," Journal of Clinical Investigation, vol. 117, no. 7, pp. 1856-1865, 2007.

[23] P. G. Gallagher, R. I. Liem, E. Wong, M. J. Weiss, and D. M. Bodine, "GATA-1 and Oct-1 are required for expression of the human $\alpha$-hemoglobin-stabilizing protein gene," Journal of Biological Chemistry, vol. 280, no. 47, pp. 39016-39023, 2005.

[24] D. Hodge, E. Coghill, J. Keys et al., "A global role for EKLF in definitive and primitive erythropoiesis," Blood, vol. 107, no. 8 , pp. 3359-3370, 2006.

[25] J. R. Keys, M. R. Tallack, D. J. Hodge, S. O. Cridland, R. David, and A. C. Perkins, "Genomic organisation and regulation of murine alpha haemoglobin stabilising protein by erythroid Kruppel-like factor," British Journal of Haematology, vol. 136, no. 1, pp. 150-157, 2007.

[26] A. M. Pilon, D. G. Nilson, D. Zhou et al., "Alterations in expression and chromatin configuration of the alpha hemoglobin-stabilizing protein gene in erythroid Krüppel-like factor-deficient mice," Molecular and Cellular Biology, vol. 26, no. 11, pp. 4368-4377, 2006.

[27] V. Viprakasit, V. S. Tanphaichitr, W. Chinchang, P. Sangkla, M. J. Weiss, and D. R. Higgs, "Evaluation of alpha hemoglobin stabilizing protein (AHSP) as a genetic modifier in patients with $\beta$ thalassemia," Blood, vol. 103, no. 9, pp. 3296-3299, 2004.

[28] C. O. Dos Santos, L. C. Dore, E. Valentine et al., "An iron responsive element-like stem-loop regulates $\alpha$-hemoglobinstabilizing protein mRNA," Journal of Biological Chemistry, vol. 283, no. 40, pp. 26956-26964, 2008.

[29] C. M. Santiveri, J. M. Pérez-Cañadillas, M. K. Vadivelu et al., "NMR structure of the $\alpha$-hemoglobin stabilizing protein: insights into conformational heterogeneity and binding," Journal of Biological Chemistry, vol. 279, no. 33, pp. 3496334970, 2004.

[30] S. Zhou, J. S. Olson, M. Fabian, M. J. Weiss, and A. J. Gow, "Biochemical fates of $\alpha$ hemoglobin bound to $\alpha$ hemoglobinstabilizing protein AHSP," Journal of Biological Chemistry, vol. 281, no. 43, pp. 32611-32618, 2006.

[31] T. L. Mollan, X. Yu, M. J. Weiss, and J. S. Olson, “The role of alpha-hemoglobin stabilizing protein in redox chemistry, denaturation, and hemoglobin assembly," Antioxidants \& Redox Signaling, vol. 12, no. 2, pp. 219-231, 2010.

[32] V. Baudin-Creuza, C. Vasseur-Godbillon, C. Pato, C. Préhu, H. Wajcman, and M. C. Marden, "Transfer of human $\alpha$ - to $\beta$-hemoglobin via its chaperone protein: evidence for a new state," Journal of Biological Chemistry, vol. 279, no. 35, pp. 36530-36533, 2004.

[33] C. Vasseur-Godbillon, D. Hamdane, M. C. Marden, and V. Baudin-Creuza, "High-yield expression in Escherichia coli of soluble human $\alpha$-hemoglobin complexed with its molecular chaperone," Protein Engineering, Design and Selection, vol. 19, no. 3, pp. 91-97, 2006.

[34] D. Hamdane, C. Vasseur-Godbillon, V. Baudin-Creuza, G. H. B. Hoa, and M. C. Marden, "Reversible hexacoordination of $\alpha$-Hemoglobin-stabilizing Protein (AHSP) $/ \alpha$-hemoglobin versus pressure: evidence for protection of the $\alpha$-chains by their chaperone," Journal of Biological Chemistry, vol. 282, no. 9, pp. 6398-6404, 2007.

[35] D. J. Weatherall, "Phenotype-genotype relationships in monogenic disease: lessons from the thalassaemias," Nature Reviews Genetics, vol. 2, no. 4, pp. 245-255, 2001.

[36] R. Galanello, L. Perseu, N. Giagu, and G. Sole, "AHSP expression in $\beta$-thalassemia carriers with thalassemia intermedia phenotype," Blood, vol. 102, 2003, abstract no. 1881.

[37] M. D. Cappellini, C. Refaldi, and D. Bignamini, "Molecular analysis of $\alpha$-hemoglobin stabilizing protein (AHSP) in Caucasian patients with different $\beta$-thalassemia phenotype," Blood, vol. 104, 2004, 29b.

[38] C. O. dos Santos, S. Zhou, D. M. Albuquerque et al., "A natural variant sequence in the AHSP gene may impact severity of $\beta$ thalassemia," Blood, vol. 106, 2005, abstract no. 3629.

[39] Z. Wang, W. Yu, Y. Li et al., "Analysis of $\alpha$-hemoglobinstabilizing protein (AHSP) gene as a genetic modifier to the phenotype of $\beta$-thalassemia in Southern China," Blood Cells, Molecules, and Diseases, vol. 45, no. 2, pp. 128-132, 2010.

[40] B. Wang, Y. Fang, X. Guo, Z. Ren, and J. Zhang, "Transgenic human $\alpha$-hemoglobin stabilizing protein could partially relieve $\beta$ iVS-2-654-thalassemia syndrome in model mice," Human Gene Therapy, vol. 21, no. 2, pp. 149-156, 2010.

[41] A. Mai, K. Jelicic, D. Rotili et al., "Identification of two new synthetic histone deacetylase inhibitors that modulate globin gene expression in erythroid cells from healthy donors and 
patients with thalassemia," Molecular Pharmacology, vol. 72, no. 5, pp. 1111-1123, 2007.

[42] S. Pissard, C. Vasseur, F. Toutain et al., "Instable $\alpha$-hemoglobin stabilizing protein as a cause of thalassemia: proof of concept," Blood, vol. 114, 2009, abstract no. 462.

[43] T. Brillet, V. Baudin-Creuza, C. Vasseur et al., “ $\alpha$-Hemoglobin stabilizing protein (AHSP), a kinetic scheme of the action of a human mutant, AHSP," Journal of Biological Chemistry, vol. 285, no. 23, pp. 17986-17992, 2010.

[44] C. Turbpaiboon, T. Limjindaporn, W. Wongwiwat et al., "Impaired interaction of $\alpha$-haemoglobin-stabilising protein with $\alpha$-globin termination mutant in a yeast two-hybrid system," British Journal of Haematology, vol. 132, no. 3, pp. 370-373, 2006.

[45] C. Vasseur-Godbillon, M. C. Marden, P. Giordano, H. Wajcman, and V. Baudin-Creuza, "Impaired binding of AHSP to $\alpha$ chain variants: $\mathrm{Hb}$ Groene Hart illustrates a mechanism leading to unstable hemoglobins with $\alpha$ thalassemic like syndrome," Blood Cells, Molecules, and Diseases, vol. 37, no. 3, pp. 173-179, 2006.

[46] P. C. Giordano, S. Zweegman, N. Akkermans et al., "The first case of Hb Groene Hart [alpha119 (H2) Pro $\rightarrow$ Ser, CCT $\rightarrow$ TCT (alpha1)] homozigosity confirms that a thalassemia phenotype is associated with this abnormal hemoglobin variant," Hemoglobin, vol. 31, no. 2, pp. 179-182, 2007.

[47] G. Lacerra, C. Scarano, G. Musollino, A. Flagiello, P. Pucci, and C. Carestia, "Hb Foggia or $\alpha 117(\mathrm{GH} 5)$ Phe $\rightarrow$ Ser: a new $\alpha 2$ globin allele affecting the $\alpha \mathrm{Hb}$-AHSP interaction," Haematologica, vol. 93, no. 1, pp. 141-142, 2008.

[48] X. Yu, T. L. Mollan, A. Butler, A. J. Gow, J. S. Olson, and M. J. Weiss, "Analysis of human $\alpha$ globin gene mutations that impair binding to the $\alpha$ hemoglobin stabilizing protein," Blood, vol. 113, no. 23, pp. 5961-5969, 2009.

[49] C. Vasseur, E. Domingues-Hamdi, T. Brillet, M. C. Marden, and V. Baudin-Creuza, "The $\alpha$-hemoglobin stabilizing protein and expression of unstable $\alpha$-Hb variants," Clinical Biochemistry, vol. 42, no. 18, pp. 1818-1823, 2009. 

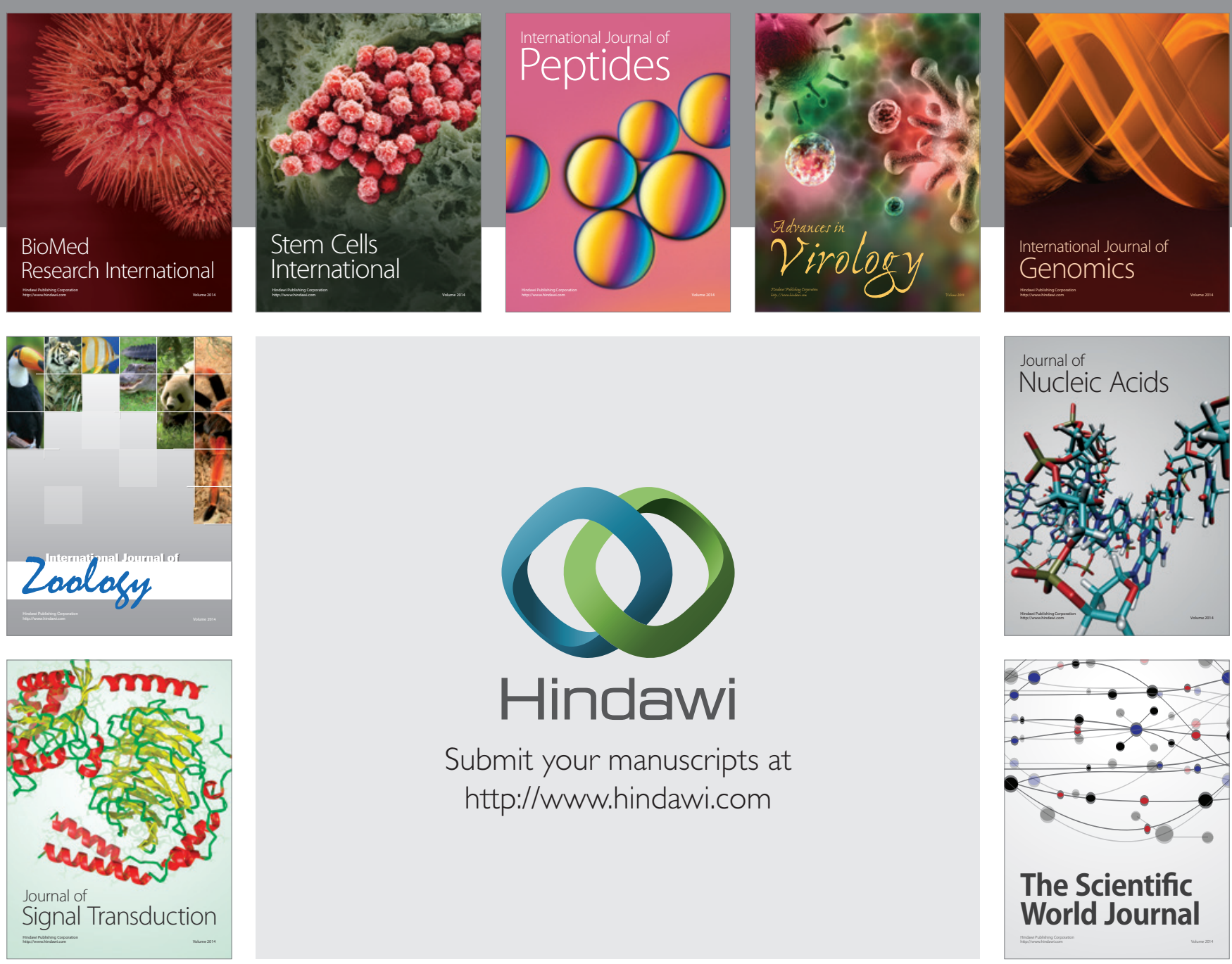

Submit your manuscripts at

http://www.hindawi.com
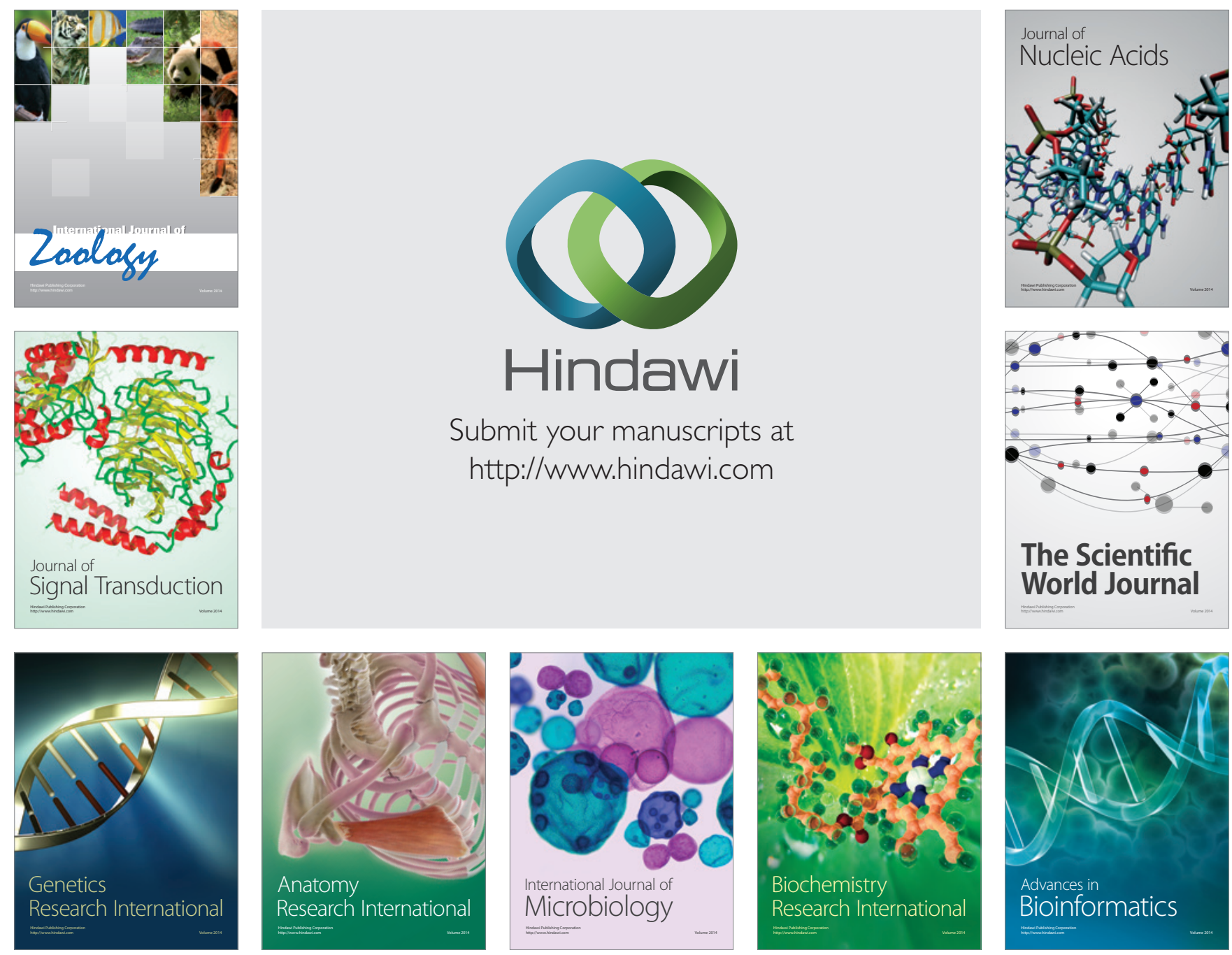

The Scientific World Journal
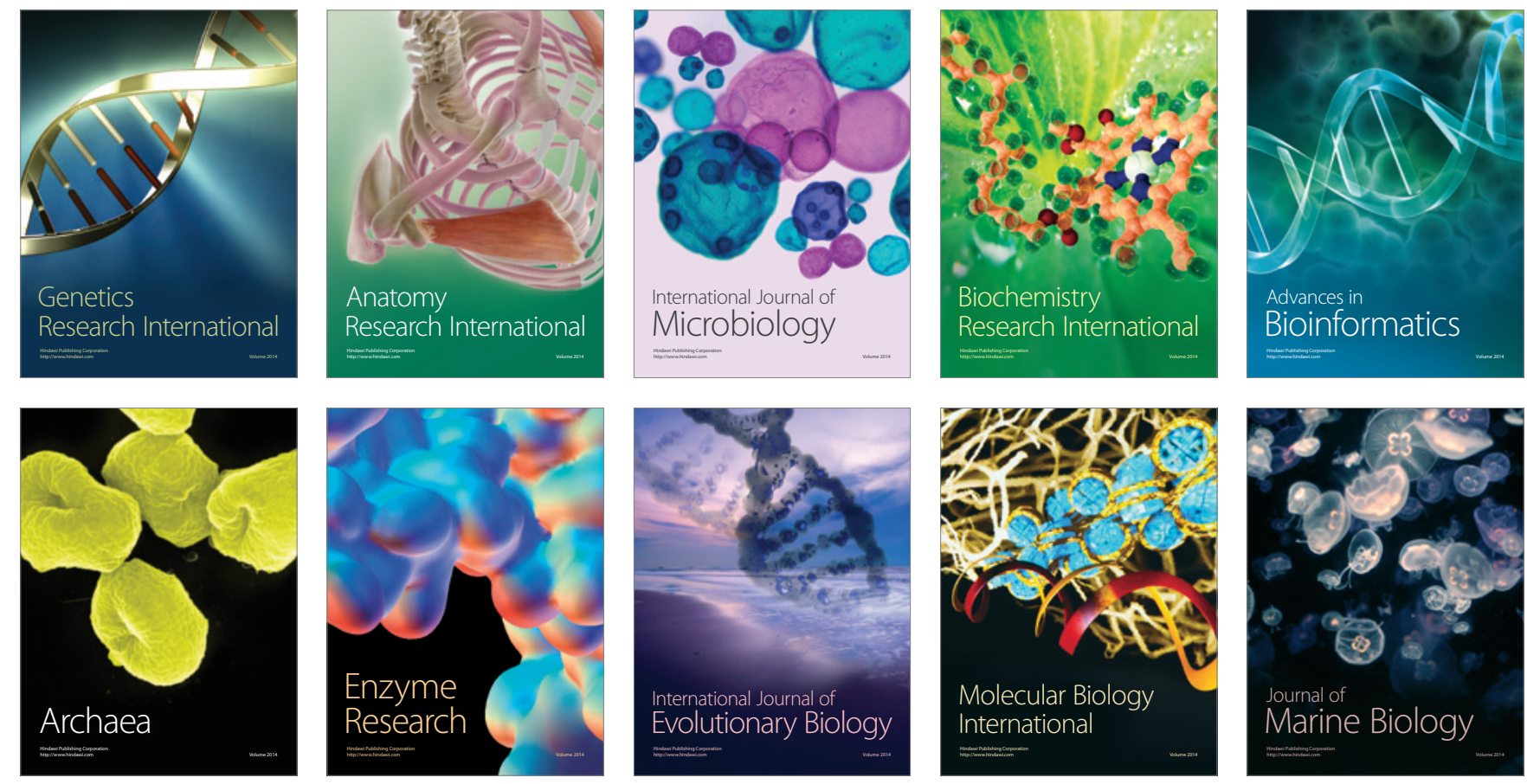